\title{
Ni-catalyzed Direct Reductive Amidation via C-O Bond Cleavage
}

\author{
Arkaitz Correa ${ }^{\dagger}$ and Ruben Martin* ${ }^{\dagger} \$$ \\ ${ }^{\dagger}$ Institute of Chemical Research of Catalonia (ICIQ), Av. Països Catalans 16, 43007, Tarragona, Spain \\ $\S$ Catalan Institution for Research and Advanced Studies (ICREA), Passeig Lluïs Companys, 23, 08010, Barcelona, Spain
}

Supporting Information Placeholder

\begin{abstract}
A novel Ni-catalyzed reductive amidation of $\mathrm{C}\left(\mathrm{sp}^{2}\right)-$ and $\mathrm{C}\left(\mathrm{sp}^{3}\right)-\mathrm{O}$ electrophiles with isocyanates is described. Such umpolung reaction allows for an unconventional preparation of benzamides by using simple starting materials and easy-to-handle Ni catalysts.
\end{abstract}

Within a few years, $\mathrm{C}-\mathrm{O}$ electrophiles have emerged as powerful and environmentally friendly alternatives to the use of organic halides in the cross-coupling arena. ${ }^{1}$ Among their advantages are the low toxicity, readily availability and natural abundance of phenols together with their unique pivotal role in organic synthesis, making them particularly attractive for further applications. Despite formidable advances, these processes are primarily restricted to the use of nucleophilic entities such as boronic acids, organozincs or Grignard reagents. ${ }^{2,3}$ Recently, catalytic reductive processes of organic halides with other electrophilic partners have received considerable attention. ${ }^{4-6}$ These methods represent a formal umpolung or a polarity inversion strategy by employing unconventional substrate combinations while avoiding the use of well-defined and stoichiometric organometallic reagents, thus changing logics in chemical reactivity and increasing our ever-growing synthetic toolkit. Strikingly, metal-catalyzed reductive events employing aryl $\mathrm{C}-\mathrm{O}$ electrophiles are relatively scarce. ${ }^{7,8}$ This might be due to the proclivity of $\mathrm{C}-\mathrm{O}$ electrophiles to undesired pathways and site-selectivity issues with multiple $\mathrm{C}-\mathrm{O}$ reaction sites, giving the notion that the use of aryl $\mathrm{C}-\mathrm{O}$ electrophiles in catalytic reductive protocols constitutes a notorious difficult challenge. Therefore, the discovery of new reactivity within this field would be a highly desirable goal of utmost synthetic importance.

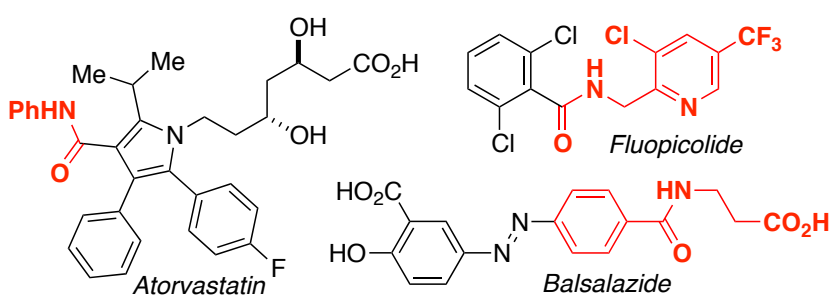

Benzamides are key structural units in a wide variety of compounds that display important biological properties such as Atorvastatin, Fluopicolide or Balsalazide, among others (Scheme 1). ${ }^{9}$ Recently, metal-catalyzed amidation protocols using well-defined and stoichiometric organometallic species (Scheme 2, path a), ${ }^{10}$ carbonylation methods using $\mathrm{CO}$ (path $\mathrm{b}$ ) ${ }^{11}$ or $\mathrm{C}-\mathrm{H}$ functionalization techniques promoted by suitable ortho-directing groups (patch c) ${ }^{12}$ have shown to be viable synthetic alternatives to classical methods for preparing such privileged motifs. ${ }^{13,14} \mathrm{We}$ envisioned that benzamides would be within reach by a reductive event using $\mathrm{C}-\mathrm{O}$ electrophiles and isocyanates, thus providing a unique opportunity to improve the efficiency and applicability of $\mathrm{C}-\mathrm{O}$ electrophiles while offering an innovative bond disconnection not apparent at first sight (path d). ${ }^{15}$ As part of our interest in $\mathrm{C}-\mathrm{O}$ bond-activation, ${ }^{16}$ we report herein the discovery of a novel catalytic protocol that deals with such challenge, exploiting a previously unrecognized opportunity in the field of $\mathrm{C}-\mathrm{O}$ bond cleavage. The method is characterized by its wide scope and excellent chemoselectivity profile, including challenging substrate combinations. Likewise, the use of readily available and airstable compounds represents an additional bonus from a practical and step-economical standpoint.

Scheme 2. Catalytic Cross-Coupling Routes to Benzamides 


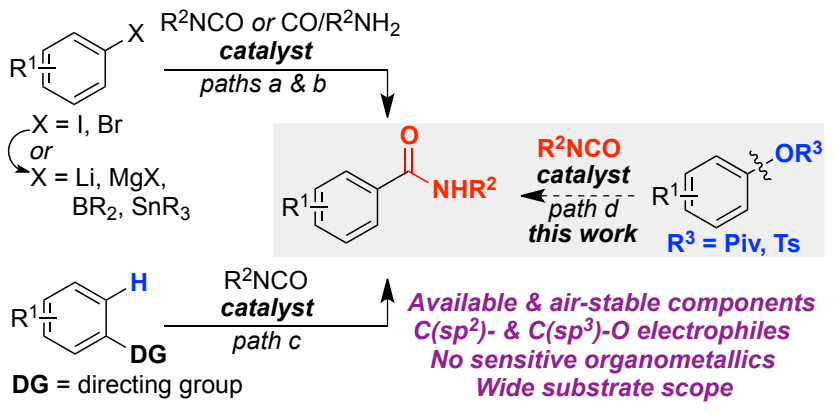

We began our investigations by examining the reactivity of 1a with $n$-butyl isocyanate using Ni precatalysts (Table 1) and the effect of all reaction parameters was systematically examined. ${ }^{17}$ As for other catalytic reductive processes, ${ }^{4-6}$ we anticipated that the nature of the ligand would play a critical role for success. As shown in entries 1-5, this was indeed the case; while dppf provided promising results in DMA and $\mathrm{Mn}$ as reducing agent (entry 1), the use of other related ligands was rather unsatisfactory, not affording even traces of 2aa and invariably resulting in 2-naphthol or reduced naphthalene (entries 2-5) ${ }^{17}$ Interestingly, the replacement of Mn by $\mathrm{Zn}$ under otherwise identical reaction conditions significantly improved the yield of 2aa (entry 6). Although different Ni sources could be utilized (entries 611 ), the best results were accomplished using $\mathrm{NiCl}_{2} \cdot$ glyme (entry 11 ). Intriguingly, the inclusion of $\mathrm{K}_{2} \mathrm{HPO}_{4}$ in anhydrous DMF had a dramatic effect on reactivity, providing $\mathbf{2 a a}$ in $81 \%$ isolated yield while minimizing undesired reaction pathways such as carbamate formation or isocyanurates by trimerization of $n \mathrm{BuNCO}$ (entry 14). To put these results into perspective, control experiments revealed that $\mathrm{NiCl}_{2} \cdot$ glyme, $\mathrm{dppf}$ or $\mathrm{Zn}$ were absolutely required to promote the reductive coupling event. ${ }^{17}$

Table 1. Optimization of the Reaction Conditions ${ }^{a}$

Reductant $(2.0$ equiv)
DMA, $80^{\circ} \mathrm{C}$

${ }^{a}$ Reaction conditions: 1a $(0.50 \mathrm{mmol}), n \mathrm{BuNCO}(2.0$ equiv), [Ni] (10 mol\%), L (x mol\%), Reductant (2.0 equiv), DMA $(0.25 \mathrm{M})$ at $80{ }^{\circ} \mathrm{C}$ for $24 \mathrm{~h}^{b}{ }^{b}$ HPLC yield using anisole as internal standard. ${ }^{c} \mathrm{~K}_{2} \mathrm{HPO}_{4}$ (1.0 equiv) was added. ${ }^{d}$ DMF as solvent. ${ }^{e} \mathrm{~K}_{2} \mathrm{HPO}_{4}$ (2.0 equiv) was added. ${ }^{f}$ Isolated yield.

Encouraged by our initial results, we sought to examine the preparative scope and generality of our Nicatalyzed reductive amidation event using naphthyl pivalates as substrates (Table 2). ${ }^{18}$ As shown for 2aa2ag, moderate to good yields were obtained regardless of the substitution pattern on the isocyanate motif. Gratifyingly, minor modifications on the reaction conditions allowed for effecting the more challenging Ni-catalyzed reductive amidation of $\mathrm{C}\left(\mathrm{sp}^{3}\right)-\mathrm{O}$ bonds at room temperature (2d and $\mathbf{2 e})$. Of significant interest is the successful preparation of $\mathbf{2 e}$; in this particular case, we found that the reductive amidation event occurred exclusively at the $\mathrm{C}\left(\mathrm{sp}^{3}\right)-\mathrm{O}$ motif, leaving the proximal $\mathrm{C}\left(\mathrm{sp}^{2}\right)-\mathrm{O}$ bond intact. As for many other $\mathrm{C}-\mathrm{OPiv}$ bondcleavage processes, ${ }^{19}$ however, we found that our protocol was restricted to the use of $\pi$-extended systems, an observation that is tentatively attributed to the intermediacy of $\eta^{2}$-arene or Meisenheimer-type complexes. ${ }^{20}$

Table 2. Catalytic Reductive Amidation of Pivalates ${ }^{a, b}$

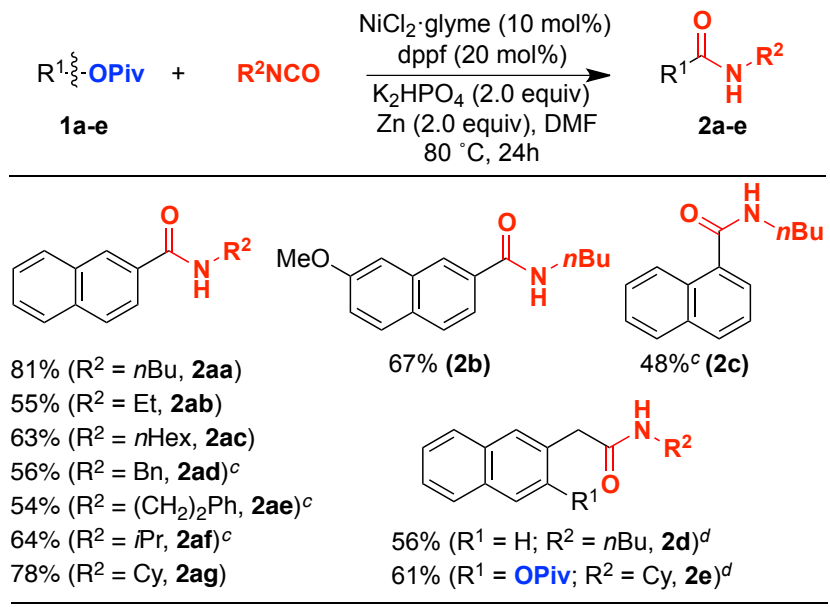

${ }^{a}$ Reaction conditions: as for Table 1 , entry $14 .{ }^{b}$ Isolated yields, average of at least two independent runs. ${ }^{c} 90{ }^{\circ} \mathrm{C}$. ${ }^{d} \mathrm{Mn}$ (2.0 equiv) at $\mathrm{rt}$.

Challenged by the limitation to $\pi$-extended systems, a further extension of the scope of this novel method was envisaged to accommodate simple phenyl derivatives. We hypothesized that the use of slightly more activated $\mathrm{C}-\mathrm{O}$ electrophiles such as aryl tosylates would be ideal for our purposes. ${ }^{21}$ Owing to their higher reactivity, however, we anticipated a certain degree of undesired dimerization events using aryl tosylates. Indeed, this turned out to be the case for most of the ligands analyzed; ${ }^{17}$ while the use of 2,2'-bypiridine provided homocoupling products quantitatively, the use of dppf as the 
ligand was found to be critical to effect the rather challenging amidation of phenyl derivatives in high yields at $60{ }^{\circ} \mathrm{C}$. Interestingly, the inclusion of $\mathrm{NaI}$ as additive totally suppressed the competitive dimerization event, an observation that is in line with other reports recently described in the literature. ${ }^{22}$ Under these reaction conditions, a wide variety of substituted phenyl tosylates smoothly underwent the desired reductive amidation process (Table 3). Blank experiments in the absence of $\mathrm{NaI}$ clearly confirmed its beneficial effect on reactivity $(\mathbf{4 c}$ and $\mathbf{4 f})$. The chemoselectivity profile is nicely illustrated by the fact that ethers $(\mathbf{4 b})$, thioethers $(\mathbf{4 e})$, ester $(\mathbf{4 g})$, nitriles $(\mathbf{4 j a} \mathbf{j} \mathbf{j b})$, pivalates $(\mathbf{4 h})$ and tosylates $(\mathbf{4 i}$, 4n) were perfectly accommodated. Of remarkable interest is the selectivity pattern observed for $\mathbf{4 h}$ and $\mathbf{4 i}$, thus leaving ample opportunities for manipulation via common cross-coupling techniques. As shown for $\mathbf{4 c}$, the reaction was not hampered by ortho substituents. Importantly, the presence of nitrogen-containing heterocycles such as pyrazole (4d), pyrrole (4I) and carbazole (4m) posed no problems, delivering the corresponding amides in good to excellent yields. Even more instructive was the successful preparation of $\mathbf{4 n}$, evidencing the selectivity profile among different $\mathrm{C}-\mathrm{OTs}$ bonds as well as the practical utility of our method for late-stage modification of biologically relevant compounds. It is worth noting that the catalytic reductive amidation of aryl chlorides (4ja, $\mathbf{4 j b}, \mathbf{4 k}$ and $\mathbf{4 l})$, particularly challenging substrates in the cross-coupling arena, ${ }^{23}$ could be conducted at room temperature under otherwise identical reaction conditions, an observation that clearly highlights the robustness and generality of our protocol. ${ }^{24,25}$

Table 3. Reductive Amidation of Aryl Tosylates ${ }^{a, b}$

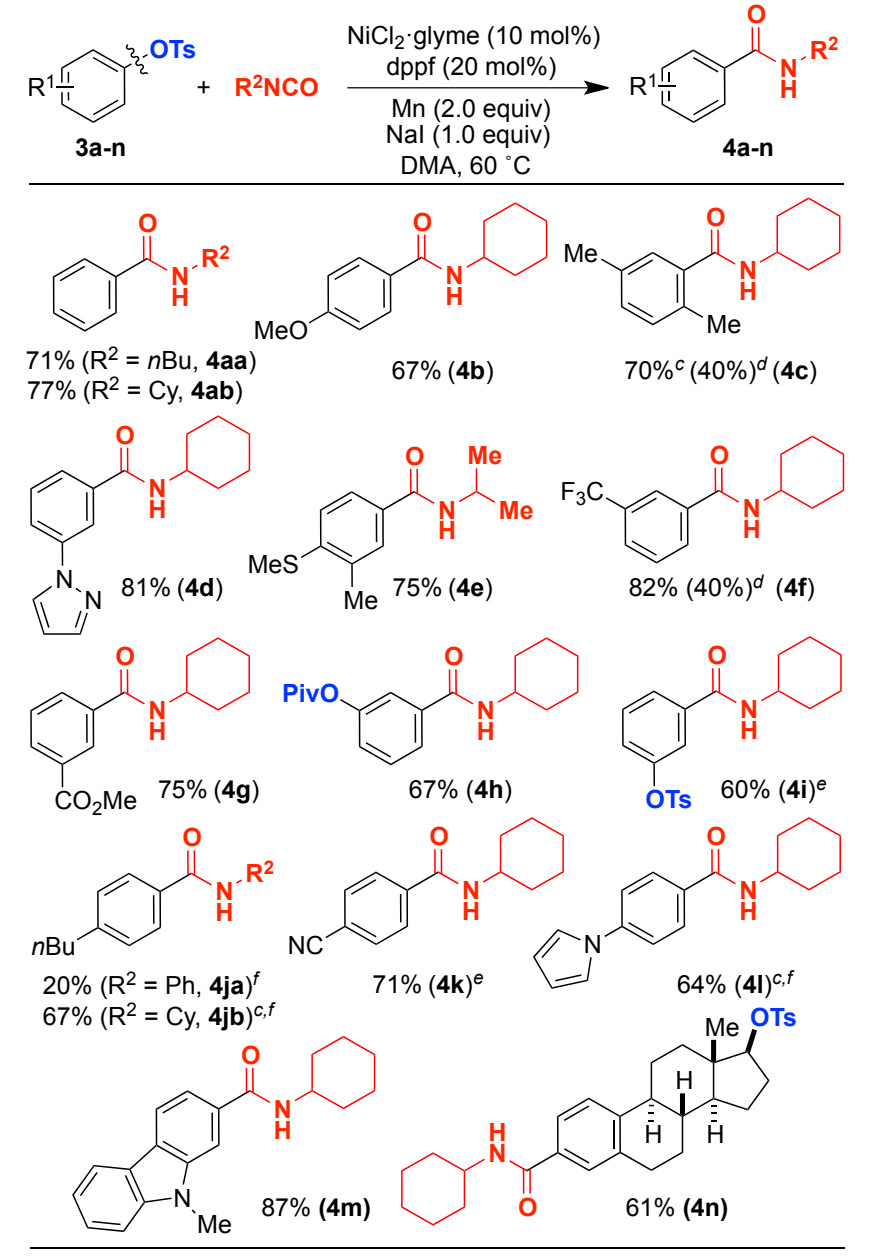

${ }^{a}$ Reaction conditions: 3a-o $(0.50 \mathrm{mmol}), \mathrm{R}^{2} \mathrm{NCO}(1.0$ mmol), $\mathrm{NiCl}_{2} \cdot$ glyme (10 mol\%), dppf (20 mol\%), NaI (1.0 equiv), Mn (2.0 equiv), DMA $(0.25 \mathrm{M})$ at $60{ }^{\circ} \mathrm{C}$ for $24 \mathrm{~h} .{ }^{b}$ Isolated yields, average of at least two independent runs. ${ }^{c}$ $48 \mathrm{~h}$ reaction time. ${ }^{d}$ In the absence of NaI. ${ }^{e} \mathrm{Mn}(1.20$ equiv). ${ }^{f}$ Reaction performed at $\mathrm{rt}$ using $\mathrm{ArCl}$ as substrate.

Although a detailed mechanistic picture requires further studies, several experiments were performed to gain insights into the reaction mechanism. We found that the catalytic reductive coupling of $\mathbf{1 a}, \mathbf{3 a}$ and $\mathbf{3 k}$ was completely inhibited by the addition of TEMPO. ${ }^{17}$ While such observation might indicate that single electron transfer processes come into play, care must be taken when generalizing this, as other radical scavengers such as BHT or galvinoxyl followed an opposite reactivity pattern. ${ }^{17}$ Interestingly, we found no reaction of $\mathbf{1 a}$ or $\mathbf{3 a}$ when replacing $n$-butyl isocyanate with butyraldehyde, thus leaving some doubt about the intermediacy of in situ generated of organomanganese or organozinc species, respectively. At present, we tentatively believe the reaction is triggered by $\mathrm{Mn}$ or $\mathrm{Zn}$-assisted reduction of $\mathrm{Ni}(\mathrm{II})$ to $\mathrm{Ni}(0)$ followed by oxidative addition into the corresponding $\mathrm{C}-\mathrm{O}$ bond. ${ }^{26}$ Subsequently, isocyanate insertion and a final transmetalation with $\mathrm{Mn}$ or $\mathrm{Zn}$ would regenerate the active $\mathrm{Ni}(0)$ species with concomitant formation of the corresponding zinc(manganese) 
amide that upon hydrolytic workup would deliver the expected product. ${ }^{27,28}$

In summary, we have described an unprecedented $\mathrm{Ni}$ catalyzed reductive amidation of $\mathrm{C}-\mathrm{O}$ electrophiles with isocyanates. This protocol constitutes a practical, userfriendly and operationally-simple strategy for the assembly of a wide range of synthetically relevant benzamides. Such formal umpolung reaction complements existing methodologies based on functional group manipulation, directing group methodologies, or the use of well-defined and air-sensitive organometallics. Further mechanistic studies and other related reductive coupling events are currently underway in our laboratories.

\section{ASSOCIATED CONTENT}

Supporting Information. Experimental procedures and spectral data. This material is available free of charge via the Internet at http://pubs.acs.org.

\section{AUTHOR INFORMATION}

\section{Corresponding Author}

*rmartinromo@iciq.es

\section{Funding Sources}

No competing financial interests have been declared.

\section{ACKNOWLEDGMENT}

We thank ICIQ Foundation, European Research Council (ERC-277883) and MICINN (CTQ2012-34054) for financial support. Johnson Matthey, Umicore and Nippon Chemical Industrial are acknowledged for a gift of metal and ligand sources. A. C. thanks MICINN for a JdC fellowship.

\section{REFERENCES}

(1) For recent reviews: (a) Tehetena, M.; Garg, N. K. Org. Process Res. Dev. 2013, 17, 29. (b) Yamaguchi, J.; Muto, K.; Itami, K. Eur. J. Org. Chem. 2013, 19. (c) Correa, A.; Cornella, J.; Martin, R. Angew. Chem., Int. Ed. 2013, 52, 1878. (d) Rosen, B. M.; Quasdorf, K. W.; Wilkson, D. A.; Zhang, N.; Resmerita, A.-M.; Garg, N.K.; Percec, B. Chem. Rev. 2011, 111, 1346. (e) Yu, D.G.; Li, B.-J.; Shi, Z.-J. Acc. Chem. Res. 2010, 43, 1486.

(2) For selected $\mathrm{C}-\mathrm{C}$ bond forming processes via $\mathrm{C}-\mathrm{O}$ bond cleavage, see: (a) Ramgren, S. D.; Hie, L.; Ye, Y.; Garg, N. K. Org. Lett. 2013, 15, 3950. (b) Amaike, K.; Muto, K.; Yamaguchi, J.; Itami, K. J. Am. Chem. Soc. 2012, 135, 14573. (c) Leowanawat, P.; Zhang, N.; Percec, V. J. Org. Chem. 2012, 77, 1018 and refereces cited therein.

(3) For selected $\mathrm{C}$-heteroatom bond forming processes via $\mathrm{C}-\mathrm{O}$ bond cleavage, see: (a) Zarate, C.; Martin, R. J. Am. Chem. Soc. 2014, 136, 2236. (b) Ramgren, S. D.; Silberstein, A. L.; Yang, Y.; Garg, N. K. Angew. Chem., Int. Ed. 2011, 50, 2171. (c) Huang, K.; Yu, D. -G.; Zheng, S. -F.; Wu, Z.-H.; Shi, Z. -J. Chem. Eur. J. 2011, 17, 786. (d) Shimasaki, T.; Tobisu, M.; Chatani, N. Angew. Chem., Int. Ed. 2010, 49, 2929.

(4) For selected catalytic reductive couplings not employing organic halides as coupling partners: (a) Montgomery, J.; Sormunen,G. J. Top. Curr. Chem. 2007, 279, 1. (b) Montgomery, J. Angew. Chem., Int. Ed. 2004, 49, 3890. (c) Moslin, R. M.; MillerMoslin, K.; Jamison, T. F. Chem. Commun. 2007, 4441. (d) Jeganmohan, M.; Cheng, C. H. Chem. Eur. J. 2008, 14, 10876.

(5) For selected recent examples of catalytic reductive coupling events of organic halides, see: (a) Shrestha, R.; Dorn, S. C. M.;
Weix, D. J. J. Am. Chem. Soc.2013, 135, 751. (b) Peng, Y.; Luo, L.; Yan, C.-S.; Zhang, J.-J.; Wang, Y.-W. J. Org. Chem. 2013, 78, 10960. (c) Cherney, A. H.; Kadunce, N. T.; Reisman, S. E. J. Am. Chem. Soc. 2013, 135, 7442. (d) Everson, D. A.; Jones, B. A.; Weix, D. J. J. Am. Chem. Soc. 2012, 134, 6146. (e) Wang, S.; Qian, Q.; Gong, H.Org. Lett. 2012, 12, 3352. (f) Wu, F.; Lu, W.; Qian, Q.; Ren, Q.; Gong, H. Org. Lett. 2012, 14, 3044.

(6) For recent catalytic reductive couplings aryl halides with $\mathrm{CO}_{2}$ : (a) Correa, A.; León, T.; Martin, R. J. Am. Chem. Soc. 2014 136, 1062. (b) León, T.; Correa, A.; Martin, R. J. Am. Chem. Soc. 2013, 135, 1221. (c) Tran-Vu, H.; Daugulis, O. ACS Catal. 2013, 3, 2417. (d) Fujihara, T.; Nogi, K.; Xu, T.; Terao, J.; Tsuji, Y. J. Am. Chem. Soc. 2012, 134, 9106. (e) Correa, A.; Martin, R. J. Am. Chem. Soc. 2009, 131, 15974.

(7) For remarkable exceptions using $\mathrm{CO}_{2}$ or $\mathrm{CO}$ as coupling partner, see: (a) ref. 6a. (b) ref. 6d. (c) Kotsuki, H.; Datta, P. K.; Suenaga, H. Synthesis 1996, 470.

(8) For the use of related activated allyl $\mathrm{C}-\mathrm{O}$ electrophiles in reductive cleavage events, see: (a) Tan, Z.; Wang, X.; Zang, Z.; Qian, Q.; Deng, W.; Gong, H. Chem. Commun. 2014, 50, 3827. (b) Anka-Lufford, L. L.; Prinsell, M. R.; Weix, D. J. J. Org. Chem. 2012, 77, 9989.

(9) (a) Pattabiraman, V.R.; Bode, J. W. Nature 2011, 480, 471. (b) Arthur, G. The Amide Linkage: Selected Structural Aspects in Chemistry, Biochemistry, and Materials Science (WileyInterscience, 2000).

(10) For selected examples, see: (a) Lygin, A. V.; de Meijere, A. Org. Lett. 2009, 11, 389. (b) Kianmehr, E.; Rajabi, A.; Ghanbari, M. Tetrahedron Lett. 2009, 50, 1687. (c) Chorell, E.; Das, P.; Almqvist, F. J. Org. Chem. 2007, 72, 4917. (d) Miura, T.; Takahashi, Y.; Murakami, M. Chem. Commun. 2007, 3577. (e) Koike, T.; Takahashi, M.; Arai, N.; Mori, A. Chem. Lett. 2004, 1364. (f) Christophersen, C.; Begtrup, M.; Ebdrup, S.; Petersen, H.; Vedsø, P. J. Org. Chem. 2003, 68, 9513.

(11) For reviews, see: (a) Brennführer, A.; Neumann, H.; Beller, M. Angew. Chem., Int. Ed. 2009, 48, 4114. (b) Li, Y.; Xue, D.; Wang, C.; Liu, Z.; Xiao, J. Chem. Commun. 2012, 48, 1320.

(12) For selected examples, see: (a) Shin, K.; Ryu, J.; Chang, S. Org. Lett. 2014, DOI 10.1021/o1500602b. (b) Zhou, B.; Hou, W.; Yang, Y.; Li, Y. Chem. Eur. J. 2013, 19, 4701. (c) Muralirajan, K.; Parthasarathy, K.; Cheng, C.-H. Org. Lett. 2012, 14, 4262. (d) Hesp, K. D.; Bergman, R. G.; Ellman, J. A. J. Am. Chem. Soc. 2011, 133, 11430 .

(13) For classical synthetic methods en rote to benzamides, see: (a) El-Faham, A.; Albericio, F. Chem. Rev. 2011, 111, 6557. (b) Valeur, E.; Bradley, M. Chem. Soc. Rev. 2009, 38, 606.

(14) For alternate oxidative catalytic amidation of alcohols or amines, see: (a) De Sarkar, S.; Studer, A. Org. Lett. 2010, 12, 1992. (b) Yoo, W.-J.; Li, C.-J. J. Am. Chem. Soc. 2006, 128, 13064. (c) Gunanathan, C.; Ben-David, Y.; Milstein, D. Science 2007, 317, 790. (d) Nordstrøm, L. U.; Vogt, H.; Madsen, R. J. Am. Chem. Soc. 2008, 130, 17672 .

(15) For the reductive cleavage of organic halides with isocyanates: Hsieh, J.-C.; Cheng, C.-H. Chem. Commun. 2005, 4554.

(16) (a) Cornella, J.; Martin, R. Org. Lett. 2013, 15, 6298. (b) Cornella, J.; Gómez-Bengoa, E.; Martin, R. J. Am. Chem. Soc. 2013, 135, 1997. (c) Álvarez-Bercedo, P.; Martin, R. J. Am. Chem. Soc. 2010, 132, 17352. (e) see ref. 3a and 6a.

(17) See supporting information for more details.

(18) The use of other related $\mathrm{C}\left(\mathrm{sp}^{2}\right)-\mathrm{O}$ electrophiles such as naphthyl acetates, carbamates or benzoates provided amide $\mathbf{2 a a}$ in comparatively much lower yields. See ref. 17 .

(19) For selected $\mathrm{C}-\mathrm{O}$ activation events limited to the use of $\pi$ extended systems, see for example: (a) Wisniewska, H. M.; Swift, E. C.; Jarvo, E. R. J. Am. Chem. Soc. 2013, 135, 9083. (b) Taylor, B. L.; Harris, M. R.; Jarvo, E. R. Angew. Chem., Int. Ed. 2012, 51, 7790. (c) Taylor, B. L. H.; Swift, E. C.; Waetzig, J. D.; Jarvo, E. R. J. Am. Chem. Soc. 2011, 133, 389. (d) Yu, D.-G.; Shi, Z.-J. Angew. Chem., Int. Ed. 2011, 50, 7097. (e) Yu, D.-G.; Li, B.-J.; Zheng, S.-F.; Guan, B.-T.; Wang, B.-Q.; Shi, Z.-J. Angew. Chem., Int. Ed. 2010, 49, 4566. 
(20) See for example: (a) Tobisu, M.; Shimasaki, T.; Chatani, N. Angew. Chem., Int. Ed. 2008, 47, 4866. (b) Ref. 6a. (c) Ref. 16b. (d) Brauer, D. J.; Krueger, C. Inorg. Chem. 1977, 16, 884. (e) Chatt, J.; Duncanson, L. A.; Venanzi, L. M. J. Chem. Soc. 1955, 4456.

(21) A comparative study of a variety of activated $\mathrm{C}\left(\mathrm{sp}^{2}\right)-\mathrm{O}$ electrophiles led us to identify aryl tosylates as the most suitable electrophiles; other groups such as aryl triflates or sulfamates were found much less efficient in our reductive amidation protocol. See ref. 17.

(22) The use of $\mathrm{NaI}$ and other iodide sources as additives has found to be beneficial in Ni-catalyzed reductive coupling reactions, see: (a) Prinsell, M. R.; Everson, D. A.; Weix, D. J. Chem. Commun. 2010, 5743. (b) Iyoda, M.; Otsuka, H.; Sato, K.; Nisato, N.; Oda, M. Bull.Chem. Soc. Jpn. 1990, 63, 80. (b) Iyoda, M.; Sakaitini, M.; Otsuka, H.; Oda, M. Chem. Lett. 1985, 127. (c) Piber, M.; Jensen, A. E.; Rottländer, M.; Knochel, P. Org. Lett. 1999, 1, 1323. (d) Ref 5d.

(23) For reviews dealing with cross-coupling reactions of aryl chlorides, see: (a) Littke, A. F.; Fu, G. C. Angew. Chem., Int. Ed. 2002, 41, 4176. (b) Grushin, V. V.; Alper, H. Chem. Rev. 1994, 94, 1047.

(24) These results are in sharp contrast with the use of aryl iodides or bromides for similar purposes at high temperatures; see ref. 15 .

(25) Aryl isocyanates could not be utilized as coupling partners in catalytic reductive amidation processes with either aryl pivalates or tosylates. In all cases analyzed, we found considerable amounts of isocyanurates via trimerization of the aryl isocyanate. Such trimerization is well-documented in the presence of zerovalent metal complexes. See for example: (a) Paul, F.; Moulin, S.; Piechaczyk, O.; Le Floch, P.; Osborn, J. A. J. Am. Chem. Soc. 2007, 129, 7294. (b) Foley, S. R.; Yap, G. P.; Richeson, D. S. Organometallics 1999, 18, 4700. (c) Tang, J.-S.; Verkade, J. G. Angew. Chem., Int. Ed. Engl. 1993, 32, 896.

(26) Muto, K.; Yamaguchi, J.; Lei, A.; Itami, K. J. Am. Chem. Soc. 2013, 135, 16384.

(27) While not entirely conclusive, such scenario was supported by the fact that chloro(1-naphthyl)(dppf)nickel(II) was catalytically competent as reaction intermediate under the optimized reaction conditions.

(28) The available data, however, does not allow us to rigorously rule out $\mathrm{Ni}(\mathrm{I})$ intermediates via single electron transfer processes or comproportionation events. For some references in this regard: (a) Goldup, S. M.; Leigh, D. A.; McBurney, R. T.; McGonigal, P. R.; Plant, A. Chem. Sci. 2010, 1, 383. (b) Ref. 5a, 6a, 6b, 6d, $16 \mathrm{~b}$ and 22a. (c) Velian, A.; Lin, S.; Miller, A. J. M.; Day, M. W.; Agapie, T. J. Am. Chem. Soc. 2010, 132, 6296. (d) Jones, G. D.; Martin, J. L.; McFarland, C.; Allen, O. R.; Hall, R. E.; Haley, A. D.; Brandon, R. J.; Konovalova, T.; Desrochers, P. J.; Pulay, P.; Vicic, D. A. J. J. Am. Chem. Soc. 2006, 128, 13175.

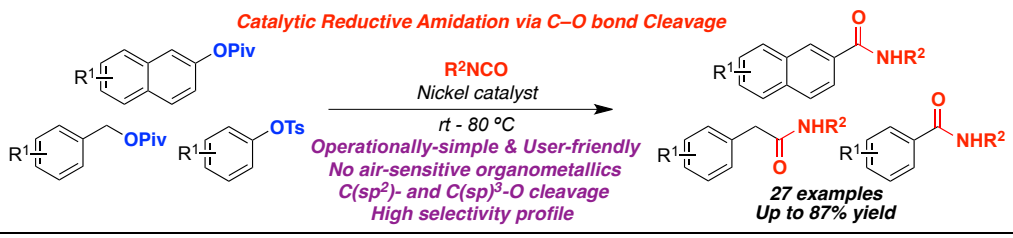

